\title{
Analyzing Languages and Communication Textbooks in the Context of Achieving Competence: Student as a Critical Thinker
}

\section{Hatixhe Ismajli}

Assoc. Prof., University of Prishtina, Kosovo, hatixhe.ismajli@uni-pr.edu

\section{Merita Neziri}

MA of Teaching and Curriculum, Teacher in Primary school, Kosovo, meritaneziri22@gmail.com

This research aims at examining and analyzing the potential that textbooks in the field of Languages and Communication provide in achieving the competence: student as a critical thinker. The data on the textbooks is collected according to the Delphi report, which is used as a standardized report in available published research on the development of critical thinking. The file extracted from this report is used as a research tool. In Kosovo, 85 Grade-5 students were involved as participants in the report as well, while the data was collected through a survey by the questionnaire for students utilized as a research tool. Mixed method was selected for research design since it includes both quantitative and qualitative research methods, while descriptive analysis method was also used during the textbooks review. The results obtained from the research indicate that the textbooks used by Kosovo students in elementary school which contain the highest potential for critical thinking development are Reading 5and Exploring English 1, while the textbook that has the lowest potential for critical thinking, is Albanian Language 5. The most developed dimensions in these textbooks are Interpretation and Analysis, while the least developed dimensions are Assessment and Inference of knowledge.

Keywords: new curriculum, languages, communication, textbooks, critical thinking, student

\section{INTRODUCTION}

Textbooks as primary sources in acquiring, expanding and complementing knowledge are inseparable part of teachers' and students' work. While the textbook was mainly 'in the function of acquisition based on students' engagement in the process of numerous repetitions, today it is used for the development of intellectual activity in acquiring new knowledge" (Zylfiu, 2011, p. 301). Textbooks reflect the course content whereas by 
their use students' main competences are developed. According to the New Competencies-based Curriculum, competences are expressed through learning outcomes envisioned to be attained progressively and continuously by all students. Nevertheless, textbooks in use designed before the implementation of the new curriculum are considered inadequate. This problem makes the implementation of the new curriculum rather challenging, and at long run, this may influence students' results. Based on this ascertainment, as well as on the requirements foreseen in the New Curriculum, the rationale of the present study is determined by our interest to explore to what extent the textbooks in the field of languages and communication influence the attainment of the competence student -a critical thinker.

Textbooks assessment would involve the careful selection of materials, examining whether they reflect the needs of learners, the aims, methods, and values of a specific teaching program (Cunningsworth, 1995). The new curriculum leads students to reflect on the contents in the textbook and aims to achieve the provisioned competencies. Some researchers consider the curriculum as a "learning plan, where objectives determine what kind of learning is important" (Ornstein\& Hunkins, 2003, p. 15). The researchers argue that curriculum should directly involve nationalism and identity rather than passions and emotions (Pinar, 2013). Working with the curriculum requires monitoring of the quality of learning and students' achievements (Walker, 2002). Students receive the most significant amount of information from textbooks. At the same time, textbooks are the major sources of contact for students. Since thinking of children is of great importance for their cognitive development, the New Curriculum Framework also includes the competence of thinking, which has as "ultimate result student as a critical thinker" (MEST, 2016, p. 17). At the same time, textbooks are the major sources of contact for students. Since thinking of children is of great importance for their cognitive development, the New Curriculum Framework also includes the competence of thinking. One of the seven curricular areas is Languages and Communication, which in itself integrates the subjects of Albanian and English language. In these subjects, students should achieve the learning outcomes for the competencies defined in the Curriculum Framework.

The aim of the research was to examine and analyses the fifth-grade textbooks used in the Language and Communication field, as well as the potential they provide to students to attain the competence: critical thinker. The main objectives are to: a) analyses the fifth-grade textbooks in the field of languages and communication; b) to analyze correlations of the dimensions of critical thinking, provided by these textbooks; c) to describe the perception of students for achievement of the competence - student as a critical thinker; d) to draw conclusions and provide the necessary suggestions and recommendations.

\section{Research Questions}

The present study seeks to provide answers for the following research questions: 
1. What potential do the textbooks in the field of Languages and Communication provide, in order to make students achieve the competence of thinking, which has as ultimate result achieving of the competence: student as a critical thinker?

2. Based on the Delphi report, which dimension of critical thinking is more and which less developed in the textbooks included in this research?

3. What are the students' opinions about the compatibility of the textbooks used in the field of Languages and Communication and their influence in the development of critical thinking?

\section{Textbooks in the Field of Language and Communication}

The textbook is a fundamental and compulsory book that serves as an essential tool and source of knowledge for a particular field and with the use of which the learning objectives are achieved. The authors interpret the curriculum and transform it into learning opportunities and real operations that teachers and students can carry out (Valverde et al., 2002). Designed following the curriculum and teaching plan, and didactically shaped, the textbook should consider the psychophysical abilities of the students and the characteristics of the subject. Therefore, the textbooks are considered as conveyors of the curriculum and often referred to as curriculum material (Remillard, 2005). Designed following the curriculum and teaching plan, and didactically shaped, the textbook should consider the psychophysical abilities of the students and the characteristics of the subject. Therefore, the textbooks are considered as conveyors of the curriculum and often referred to as curriculum material (McGrath, 2002).

The textbooks in the curriculum field Languages and Communication used by the fifthgrade students are: Albanian Language 5 (five), Reading 5 (five) and Exploring English 1 (one), which were approved to be used under the MEST decision in 2007. The textbook of Albanian Language 5 contains 30 lessons or learning units and each of them has four sections: Speaking, Reading, Writing, and Language. In most cases, in this textbook questionnaire posed for students who are required to describe an event. The most frequent questions are: Where did the event take place? Who are the main characters? What happened next? Who was right in the story? What would you do if you were in this situation? These questions would require students to defend or argue their own opinion. In contrast to this textbook, the textbook Reading 5 (Syla, 2007) is seen to be more vibrant with aesthetic and literary values that incite the student's interest to read further, to comment on the learning units and to enrich their vocabulary with new words and artistic expressions.

With regard to the development of critical thinking of students, this textbook provides more opportunities for knowledge reinforcement. Thus, the analysis of poems or literary texts is made by encouraging students to create something new or to describe the poem they read. Every teacher must help students resolve their problems independently and find new relevant information, present and evaluate the views of others, (Steele\&Meredith, 2002). Textbooks used by students are a stimulating factor in developing critical thinking. Having the book at the core is entirely in compliance with the importance paid to the written word as the primary means of education. 
The teaching of the English Language is made through the textbook Exploring English 1 (Harris \& Rowe, 2006). This textbook also includes a considerable amount of writing exercises that are required to be completed by students in the classroom. The book also has the grammar section but does not provide many opportunities to handle more extensive activities.

\section{A student as a Critical Thinker}

From a student-centered perspective and competencies-based work, it is essential for the textbooks to motivate students and stimulate their progress. Studies have shown that books play a crucial role in the development of critical thinking of students (Errington\& Bubna-Litic, 2015). The notion "critical thinking" is used to describe thinking that is purposeful, reasoned and goal-directed. It is the kind of thinking involved in solving problems, formulating inferences, calculating likelihoods, and making decisions (Halpern, 2003). The teacher develops this ability in students by the use of curriculum materials available, which may have sufficient potential for development of students' critical thinking. Access to learning resources and the use of a broader spectrum will avoid the routine learning and memorizing by students and will provide opportunities for deep learning. It is possible to impart on students a million facts and still leave them completely uneducated (Snyder \& Snyder, 2008). The student should analyze the material and not just be part of the text, but move on beyond the text level, using a highlevel thinking, be as critical and creative as possible, explore in depth the material but always driven by the content itself. Teachers are the ones who can instill the idea of high-level thinking in students by encouraging them to think about different problems critically (Zohar, 2004). Skills for their development are categorized into four groups: clarity, assessment of experiences, making interference judgments and using appropriate strategies and techniques (Bullen, 2007). To think critically, a person needs to possess some basic skills, such as: the ability to listen, to observe, to evaluate, to conclude, to clarify, to reflect, to solve problems and to make decisions. Majority of students in schools as well as university students are failing to come up with grounded conclusions based on facts. In most cases, they are taught what to think, but few of them know how to think. Critical thinking is not just part of children's education; it is a goal that is intended to be achieved in school and this means quality in learning and not just pure knowledge (Dam, ten \&Volman, 2004).

Textbooks have a wide use in schools, in teaching and acquiring new knowledge. Teaching contents developed by teachers based on textbooks aim at the development of logical abilities and critical thinking skills. The quality of textbooks influences the quality of knowledge that students acquire through them.

Teachers should understand the cognitive processes that make up critical thinking, to know intimately the tasks, habits, and situations in which these processes can be implemented. They should also use diverse activities in the classroom, which develop these processes. Critical thinking is not a set of skills extracted from the context. This kind of thinking includes a broader field of several meta-cognitive strategies and it is intimately connected with practice. To teachers, this is not a very comfortable and easy situation, but it is not something that can block the teaching and learning process of the 
students to think more critically (Willingham, 2008). With the application of different methodologies, they can teach this kind of thinking to the students. Critical thinking of children continues to be even more complex due to the skills required for the students to have, to attain, or to acquire.

Since the year 2011, Kosovo began implementing the New Curriculum, the document that aims at the development of life-long learning skills and the creation of a sustainable education system in accordance with contemporary developments and requirements. These requirements pose the necessity for revision of textbooks and their adaptation to the New Curriculum. Little research of this nature has been conducted up to date; besides they were rather superficial. The present study differs from earlier studies by the research tools used, by processing and analytical interpretation of data, as well as by conclusions derived from the study.

The present research will provide teachers with opportunities to discern which areas of the textbook promote higher critical thinking skills. It also draws novelty from the fact that it is the first in-depth analysis of language textbook competencies and critical thinking centered around grade 5 Kosovo Albanian students.

\section{METHOD}

The present research makes use of the descriptive analysis, which "should indicate the means, standard deviations, and range of scores for variables" (Creswell, 2014, p. 163) while the collected data is of the qualitative and quantitative character (Creswell \& Plano , 2011). This method was selected since arrange of empirical techniques supports effective descriptive analyses. "Simple statistics that describe central tendencies and variation (for example, means, medians, and modes) are the most common tools of descriptive work and can be very helpful for describing data" (Loeb , 2017, p. 6). The data is processed through the SPSS program, which made possible finding of the mode, median, standard deviation and the value of Pearson's correlation coefficient. The research was conducted with students at fifth grade in Kosovo and the textbooks used by them in learning the Albanian language and the English language. These textbooks are: Albanian Language 5 (five), Reading 5 (five) and English Exploring 1 (one). Also, 85 Grade 5 (five) students have been included in the research.

\section{Participants}

The sample of this research was intentional; it comprised 85 Grade 5 (five) students as the three essential textbooks in the field of Languages and Communication for grade 5 (five) are used.

\section{Research Instruments and Design}

The present research utilized the tool of the file to evaluate the textual curriculum contents, which promote development of critical thinking as per Delphi report (Facione, 1990), which is standardized and used in critical thinking research since 1990 in Fullerton. This file contains five dimensions that measure the development of critical thinking: interpretation, analysis, assessment, conclusion, and inference. This particular file has been used earlier in other studies to measure the development of critical thinking 
in the spoken language. By identifying any curricular fact (learning opportunities for critical development, provided by the texts) in the learning units, the researchers have filled out one + file each time the curriculum facts are presented.

This research is based on 5 (five) groups of opportunities for the development of critical thinking according to the taxonomic level: Interpretation (Categorization/CT, Clarity/CL, Expressive Wealth, EW), Analysis (Outline of Ideas/OI, Clear Inference/CI, Distinct Arguments/DA), Assessment (Differentiation of Confidence/DC, Comparison of Arguments/CA), Conclusion (Related Information/RI, Alternative Explanations/AE, Presence of Conclusions/PC), Inference (Expression of Conclusions/EC, Operations/O, Inference of Conclusions/IC).

In order to ensure research reliability, the researchers used a questionnaire for students as a research tool. The questionnaire was designed with the reference to theory. "Theory serves as a conceptual tool that can move an inquiry forward toward deeper levels of understanding" (Agee, 2009, p. 438). The format used was a paper-based questionnaire with close-ended questions whereas the development of its content was based on Guidelines for categorization schema development (Ruel, E. at al., 2016). Moreover, the Delphi report was modified for the purposes of measuring the critical thinking level of students' reading capability instead of original assessment of verbal skill.

The questionnaire for students is divided into two sections: a) section one related to the Albanian language, consisting of 8 (eight) questions: 4 (four) for Albanian Language and 4 (four) for Reading, and b) section two related to the English language, consisting of 4 (four) questions. The questionnaires were based on the Liker scale with the options: fully agree, partially agree, neutral, partially disagree and fully disagree.

\section{FINDINGS}

The results derived from the analysis of textbooks based on the dimensions: Interpretation, Analysis, Assessment, Conclusion, and Inference, as well the operations of critical thinking are presented in Table 1 .

Table 1

Analysis of Textbooks Albanian Language 5, Reading 5 and Exploring English

\begin{tabular}{|c|c|c|c|c|c|}
\hline & Interpretation & Analysis & Assessment & Conclusion & Inference \\
\hline Operation & CT CL EW & OICI DA & DC CA RI & $\mathrm{AE} \mathrm{PC}$ & $\mathrm{EC} \mathrm{O} \mathrm{IC}$ \\
\hline Reading 5 & $\begin{array}{lll}20 & 65 & 107\end{array}$ & 1332614 & $\begin{array}{lll}20 & 11 & 89\end{array}$ & 2742 & $4080 \quad 10$ \\
\hline Albanian Lang.5 & $\begin{array}{lll}19 & 40 & 56\end{array}$ & $66 \quad 23 \quad 15$ & $14 \quad 1436$ & 1922 & $\begin{array}{lll}19 & 51 & 6\end{array}$ \\
\hline Exploring English 1 & $\begin{array}{lll}8 & 52 & 46\end{array}$ & $\begin{array}{lll}57 & 89 & 76 \\
\end{array}$ & $\begin{array}{lll}35 & 9 & 31\end{array}$ & 3116 & $\begin{array}{lll}18 & 20 & 16\end{array}$ \\
\hline Total dim. & 413 & 499 & 103 & 313 & 260 \\
\hline
\end{tabular}

The overall data in Table 1 with regard to the opportunities of textbooks Albanian Language 5, Reading 5 and Exploring English 1 indicate that in the field of Languages and Communication the most popular dimension is the one of the Analysis with 499 facts, followed by the one of Interpretation with 413 facts, while the least popular dimension in these textbooks is the one of Inference with 103 found facts. 
The data presented in the table also shows that the most popular Operation is Outline of Ideas/OI- (Analysis) with 256 facts, while the least present Operation is Inference of Conclusions/IC-(Inference) with 32 facts.

The research has also revealed that these textbooks do not provide sufficient opportunities for assessment of different activities and situations. The textbooks elaborate well a given idea and this is their priority; however, the conclusions drawn are not sufficiently grounded.

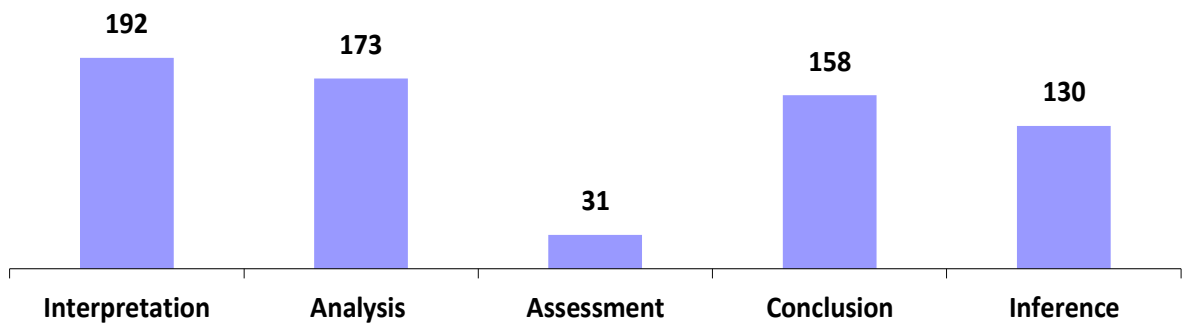

Figure 1

Critical Thinking Development in the Textbook Reading 5

After having analyzed the textbooks, the findings have shown that in the textbook Reading 5 the most popular dimension is the one of Interpretation with 192 interpretation possibilities of the learning units, and the least popular is the one of Assessment with 31 facts.

The data indicates that this particular textbook does not provide sufficient opportunities to compare the arguments within a learning unit, hence it does not provide a significant opportunity for the assessment of activities within the textbook.

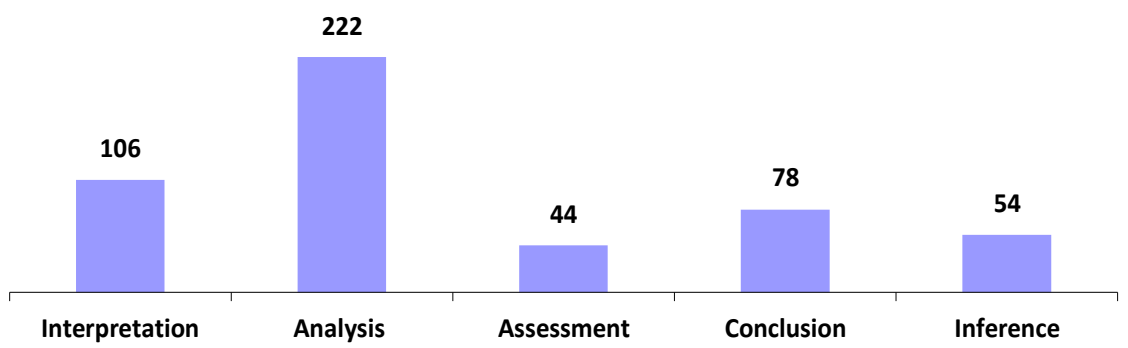

Figure 2

Critical Thinking Development in the Textbook English Exploring 1 
Referring to Figure 2, it is obvious that in the textbook Exploring English 1, the most popular dimension is the one of Analysis. This dimension carries out three operations: discussion of ideas, clear inference, and clear arguments.

It is worth pointing out that in this textbook the most popular Operation is Analysis with 89 facts presented, whereas the least is Interpretation with eight presented facts, while the one of Assessment is presented with nine facts evidenced.

Based on these findings, it can be concluded that the English Language textbook is prone to providing information through different learning figures and illustrations, and this is considered a positive point of the text. English textbooks are actually ambassadorial cultural artefacts and that students should not only critically engage with their books but also view them as more than mere linguistic objects (Grey, 2000). From the chart presented above, it can be seen that the least popular dimension is the one of Assessment presented with 44 facts found in the textbook.

Correlation between dimensions for critical thinking in the field of Languages and Communication

Table 2

Correlation between Dimensions for Critical Thinking (Textbook Albanian Language 5)

\begin{tabular}{|c|c|c|c|c|c|}
\hline & Interpretation & Analysis & Assessment & Conclusion & Inference \\
\hline \multicolumn{6}{|l|}{ Interpretation } \\
\hline Pearson Correlation & 1 & -.123 & -.189 & -.275 & .104 \\
\hline Sig. (2-tailed) & & .504 & .301 & .128 & .570 \\
\hline $\mathrm{N}$ & 33 & 32 & 32 & 32 & 32 \\
\hline \multicolumn{6}{|l|}{ Analysis } \\
\hline Pearson Correlation & -.123 & 1 & $.617 * *$ & $.424 *$ & $.362 *$ \\
\hline Sig. (2-tailed) & .504 & & .000 & .014 & .042 \\
\hline $\mathrm{N}$ & 32 & 35 & 33 & 33 & 32 \\
\hline \multicolumn{6}{|l|}{ Assessment } \\
\hline Pearson Correlation & -.189 & $.617 * *$ & 1 & .330 & .045 \\
\hline Sig. (2-tailed) & .301 & .000 & & .060 & .806 \\
\hline $\mathrm{N}$ & 32 & 33 & 34 & 33 & 32 \\
\hline \multicolumn{6}{|l|}{ Conclusion } \\
\hline Pearson Correlation & -.275 & $.424 *$ & .330 & 1 & .247 \\
\hline Sig. (2-tailed) & .128 & .014 & .060 & & .173 \\
\hline $\mathrm{N}$ & 32 & 33 & 33 & 33 & 32 \\
\hline \multicolumn{6}{|l|}{ Inference } \\
\hline Pearson Correlation & .104 & $.362 *$ & .045 & .247 & 1 \\
\hline Sig. (2-tailed) & .570 & .042 & .806 & .173 & \\
\hline $\mathrm{N}$ & 32 & 32 & 32 & 32 & 32 \\
\hline
\end{tabular}

**. Correlation is significant at the 0.01 level (2-tailed).

*. Correlation is significant at the 0.05 level (2-tailed).

According to the data presented in Table 2, it can be observed that in the textbook Albanian Language 5, the dimension of Analysis correlates with the dimension of Assessment. The correlation coefficient is $\mathrm{r}=.617, \mathrm{p}=.000$. This value is statistically 
significant. Thus, it can be concluded that the correlation between the Analysis and the Assessment dimensions is strong.

On the other hand, both the dimension of Analysis and the one of Conclusion are also correlated. The correlation value $\mathrm{r}=.424, \mathrm{p}=014$ is statistically significant. The correlation between these dimensions is strong.

The data also shows that the size of the Analysis is correlated with the dimension of Inference and the coefficient of correlation is $\mathrm{r}=.362, \mathrm{p}=.042$. The correlation between these dimensions is moderate.

Table 3

Correlation between Dimensions for Critical Thinking (Textbook Reading 5)

\begin{tabular}{|c|c|c|c|c|c|}
\hline & Interpretation & Analysis & Assessment & Conclusion & Inference \\
\hline \multicolumn{6}{|l|}{ Interpretation } \\
\hline Pearson Correlation & 1 & $.293 *$ & .086 & .231 & $.294 *$ \\
\hline Sig. (2-tailed) & & .022 & .510 & .076 & .021 \\
\hline $\mathrm{N}$ & 61 & 61 & 61 & 60 & 61 \\
\hline \multicolumn{6}{|l|}{ Analysis } \\
\hline Pearson Correlation & $.293 *$ & 1 & .215 & $.261 *$ & $.270 *$ \\
\hline Sig. (2-tailed) & .022 & & .096 & .044 & .036 \\
\hline $\mathrm{N}$ & 61 & 61 & 61 & 60 & 61 \\
\hline \multicolumn{6}{|l|}{ Assessment } \\
\hline Pearson Correlation & .086 & .215 & 1 & .168 & .233 \\
\hline Sig. (2-tailed) & .510 & .096 & & .198 & .070 \\
\hline $\mathrm{N}$ & 61 & 61 & 61 & 60 & 61 \\
\hline \multicolumn{6}{|l|}{ Conclusion } \\
\hline Pearson Correlation & .231 & $.261 *$ & .168 & 1 & $.743 * *$ \\
\hline Sig. (2-tailed) & .076 & .044 & .198 & & .000 \\
\hline $\mathrm{N}$ & 60 & 60 & 60 & 60 & 60 \\
\hline \multicolumn{6}{|l|}{ Inference } \\
\hline Pearson Correlation & $.294 *$ & $.270 *$ & .233 & $.743 * *$ & 1 \\
\hline Sig. (2-tailed) & .021 & .036 & .070 & .000 & \\
\hline $\mathrm{N}$ & 61 & 61 & 61 & 60 & 61 \\
\hline
\end{tabular}

*. Correlation is significant at the 0.05 level (2-tailed).

**. Correlation is significant at the 0.01 level (2-tailed).

Table 3 presents the data which show that in the textbook Reading 5 the dimension of Interpretation and the one of Analysis are correlated and the coefficient of correlation has a significant value of $\mathrm{r}=.293, \mathrm{p}=0.22$; however, the correlation expressed between these dimensions is weak.

The dimension of Interpretation and Inference are also correlated, and the correlation coefficient is weak, $\mathrm{r}=.294, \mathrm{p}=.021$. The dimension of Analysis and Conclusion are correlated too, and the correlation coefficient is $r=.261, p=0.44$, and this is statistically significant. Based on the values of correlation coefficient, the correlation between these dimensions is considered weak. 
The dimensions of Analysis and Inference are correlated, and the correlation coefficient is $\mathrm{r}=.270, \mathrm{p}=.036$. The correlation expressed between these two dimensions is weak. The dimension of Conclusion and Inference are correlated as well, while the correlation coefficient is $r=.743, p=.000$, and this shows statistical significance.

Table 4

Correlations between the Dimensions of Critical Thinking (Textbook English Exp.1)

\begin{tabular}{|c|c|c|c|c|c|}
\hline & Interpretation & Analysis & Assessment & Conclusion & Inference \\
\hline \multicolumn{6}{|l|}{ Interpretation } \\
\hline Pearson Correlation & 1 & .085 & $.289 *$ & $.382 * *$ & $.414 * *$ \\
\hline Sig. (2-tailed) & & .546 & .036 & .005 & .002 \\
\hline $\mathrm{N}$ & 53 & 53 & 53 & 53 & 52 \\
\hline \multicolumn{6}{|l|}{ Analysis } \\
\hline Pearson Correlation & .085 & 1 & $.352 * *$ & .020 & .034 \\
\hline Sig. (2-tailed) & .546 & & .009 & .885 & .813 \\
\hline $\mathrm{N}$ & 53 & 64 & 54 & 53 & 52 \\
\hline \multicolumn{6}{|l|}{ Assessment } \\
\hline Pearson Correlation & $.289 *$ & $.352 * *$ & 1 & .217 & .201 \\
\hline Sig. (2-tailed) & .036 & .009 & & .118 & .154 \\
\hline $\mathrm{N}$ & 53 & 54 & 55 & 53 & 52 \\
\hline \multicolumn{6}{|l|}{ Conclusion } \\
\hline Pearson Correlation & $.382 * *$ & .020 & .217 & 1 & $.661 * *$ \\
\hline Sig. (2-tailed) & .005 & .885 & .118 & & .000 \\
\hline $\mathrm{N}$ & 53 & 53 & 53 & 53 & 52 \\
\hline \multicolumn{6}{|l|}{ Inference } \\
\hline Pearson Correlation & $.414 * *$ & .034 & .201 & $.661 * *$ & 1 \\
\hline Sig. (2-tailed) & .002 & .813 & .154 & .000 & \\
\hline $\mathrm{N}$ & 52 & 52 & 52 & 52 & 53 \\
\hline
\end{tabular}

*. Correlation is significant at the 0.05 level (2-tailed).

**. Correlation is significant at the 0.01 level (2-tailed).

According to the data presented in Table 4., it can be seen that in Exploring English 1 textbook, the correlation coefficient between the dimensions of Interpretation and Analysis is $\mathrm{r}=.289, \mathrm{p}=.036$ and this is statistically significant. The correlation between these dimensions is weak.

The dimensions of Interpretation and Conclusion are also correlated, and the coefficient of correlation is $\mathrm{r}=.382, \mathrm{p}=.005$, thus the correlation expressed between these two dimensions is moderate. The dimension of Interpretation is in correlation with the dimension of Inference, where the coefficient of correlation is $r=.414, p=.002$. Hence, the correlation expressed between these two dimensions is strong.

The dimension of the Analysis is in correlation with the Assessment dimension, and the correlation coefficient is $\mathrm{r}=.352, \mathrm{p}=.009$, whereas the correlation expressed between these two dimensions is moderate.

The Conclusion dimension is in correlation with the Inference dimension, and the correlation coefficient is $\mathrm{r}=.661, \mathrm{p}=.000$, being thus statistically significant. The correlation between these dimensions is strong. 


\section{Findings from the Questionnaire with Students}

As discussed in the Research Methodology section, the questionnaire comprised the total of 12 questions, 8 for the Albanian Language and 4 for the English language. These two subjects comprise the Languages and Communication field of the New Curriculum. The results of one of the questions for each of the languages, more precisely one for Albanian and one for English were selected since the results presented below are closer to providing the answer for the third research question.

The following data is collected from the statement related to the textbook of the Albanian language: Textbooks we use in the subject of the Albanian language provoke in me curiosity to draw conclusions and to ground them:

Table 5

Drawing Conclusion and Inference of Events (Albanian Language Textbook)

\begin{tabular}{llccc}
\hline & Frequency & Percent & Valid Percent & Cumulative Percent \\
\hline Fully agree & 15 & 17.6 & 17.6 & 17.6 \\
Partially agree & 15 & 17.6 & 17.6 & 35.3 \\
Neutral & 24 & 28.2 & 28.2 & 63.5 \\
Partially disagree & 9 & 10.6 & 10.6 & 74.1 \\
Fully disagree & 22 & 25.9 & 25.9 & 100.0 \\
Total & 85 & 100.0 & 100.0 & \\
\hline
\end{tabular}

Table 6

The Number of Students and Statistical Analysis

\begin{tabular}{lcccl}
\hline Total no of students & Mean & Median & Mode & Std. Deviation \\
\hline 85 & 3.094 & 3.0000 & 3.00 & 1.42781 \\
\hline
\end{tabular}

Based on the statistical data of the responses, the arithmetic mean of responses is 3.0941 , while the median of responses is 3 and the mode is 3.00 , whereas the standard deviation has the value of 1.42781. Based on this, it is considered that standard deviation is higher in this case as it is far from the arithmetic mean. In general, the students have a neutral attitude towards this statement and some students (25.9\%) fully disagree with this statement. Consequently, it is considered that textbooks of the Albanian language, to a considerable extent, do not encourage students to draw conclusions about the lessons units and to justify them.

In the section of responses related to the textbook of the English Language subject, on the statement: In the English Language textbook we find many opportunities to provide our independent opinion, the results are as follows:

Table 7

English Language Textbook and Independent Thinking of Students

\begin{tabular}{lcccc}
\hline & Frequency & Percent & Valid Percent & Cumulative Percent \\
\hline Fully agree & 3 & 3.5 & 3.5 & 3.5 \\
Partially agree & 12 & 14.1 & 14.1 & 17.6 \\
Neutral & 13 & 15.3 & 15.3 & 32.9 \\
Partially disagree & 30 & 35.3 & 35.3 & 68.2 \\
Fully disagree & 27 & 31.8 & 31.8 & 100.0 \\
Total & 85 & 100.0 & 100.0 & \\
\hline
\end{tabular}


Table8

The Number of Students and Statistical Analysis

\begin{tabular}{llrll}
\hline Total no of students & Mean & Median & Mode & Std. Deviation \\
\hline 85 & 3.7765 & 4.0000 & 4.00 & 1.14825 \\
\hline
\end{tabular}

Table 7 and 8 show that the arithmetic mean equals 3.77, while the median is 4.00 , and this makes it understandable that according to the responses of the students, the average of their responses is: partially disagree, and this is considered a weakness of the textbook Exploring English 1. Besides, from the statistical data, it is seen that the mode of students' responses to this statement is 4.00 (partially disagree), while the standard deviation is 1.14825 which means that there is significant distribution of students' opinions on Liker scale of responses.

\section{DISCUSSION}

Textbooks are an essential source in the curricula of language and students benefit considerably from the teaching process (Harmer, 2007). As such, they play an important role in the development of critical thinking. Textbooks provide input into classroom lessons in the form of texts, activities, explanations, and so on (Hutchinson\&Torres, 1994). Students take the most substantial amount of information from textbooks, and they have the most extensive contact with them.

The studies conducted earlier in Kosovo on the textbooks for grades 6-9 (Thaci, 2010) show that promotion of critical thinking is not sufficiently addressed, whereas in primary education (grades 1-5) it is not addressed at all.

The present study is based on the analysis of three textbooks in the field of Languages and Communication. The advantages of using these textbooks are that they are psychologically essential for students, since their progress and achievement can be measured concretely when we use them (Haycroft, 1998).

Based on the results obtained from the standardized Delphi report, it is concluded that in the textbooks Albanian language 5 and Reading 5 there are three main findings:

a) the most popular dimension in the textbook Albanian language 5 is the one of Interpretation. Interpretation is about the understanding of a written text. To understand a book, the facts presented in it are required to be clearly categorized, described and expressed using a clear language. The value of this dimension in this textbook is 115 . Meanwhile, the least developed dimension in the textbook Albanian Language 5 is the one of Assessment presented with 28 curricular facts;

b) the most popular dimension in the Albanian language 5 is the Analysis presented with 66 facts, while the least popular dimension in this textbook is the one of Assessment with 14 facts;

c) The most popular dimension in the text Reading 5 is also the Interpretation presented with 192 facts.

The second finding comes from the opinions of the students surveyed, who stated that the Albanian Language 5 textbook provides excellent opportunities to express 
independent views of students and to give alternative ideas to the learning units. However, the language used in Albanian Language 5 textbook is considered to be inappropriate since in many cases it is difficult to understand. Students have different backgrounds, abilities, and needs, so every school setting is unique, and the criteria will undoubtedly be different. On the other hand, the teachers' perspective and the syllabus are two essential criteria that need to be taken into account in the assessment process (Fredriksson \& Olsson, 2006). Based, on these the relevance of ideas within a learning unit to some extent is good. However, Albanian Language 5 textbook encourages students to assess activities, but not knowledge.

In the Exploring English 1 textbook there are three main findings:

a) the most frequently encountered dimension is the one of the Analysis which is presented with 222 curricular facts evidenced. This dimension comprises three activities: elaboration of ideas, clear inference, and clear arguments;

b) the aspect that is the least encountered in the textbook Exploring English 1 is Assessment with 44 curriculum facts found in the textbook;

c) the most developed operation in this text, in general, is the one of providing clear argumentation which is presented with 89 facts.

The second finding comes from the thoughts of students, participants in the survey, who consider that this text helps students to understand the learning units using different illustrations. It is not overloaded with new words that would overstrain the student during the learning of the unit. Textbooks not only represent the visible heart of any ELT program but also offer considerable advantages for both the student and the teacher when they are being used in the EFL classroom (Sheldon, 1988). Students are active in developing different activities, but according to them, the textbooks do not provide sufficient opportunities for oral commentary of the learning units as well as for the assessment of the knowledge.

\section{CONCLUSION}

Referring to the findings and the results obtained by this research, it can be concluded that the textbook which has attained the highest number of points with regard to the potential for critical thinking development is Reading 5 with 684 facts, while the textbook with the lowest number of points regarding the potential for critical thinking development is the Albanian Language 5. Assessment of knowledge encourages students to analyze and reflect, and in this way they become sharp-witted. According to Lynch, evaluation is a systematic effort for gathering information in order to make judgments and decisions (Lynch, 1996). The most prevalent dimensions in these texts are the Analysis and the Interpretation, while the least ones are the Assessment and the Inference. Based on the data, it is considered that the textbooks elaborate well on a given concept and this is their advantage, but they do not sufficiently ground the conclusions, and this is seen as their weakness. The emphasis in education is shifting from the acquisition of facts to the process of thinking (Lipman, 1984). In this regard, it 
can be concluded that the textbooks of the Languages and Communication field can partially ensure attainment of the competence of critical thinking.

Based on what has been stated above, it is recommended that the publishers of the respective textbooks, in the next publishing, take into consideration the necessity to increase the presence of the Assessment dimension with curricular facts. Teachers also should use more materials to encourage students to compare arguments and draw conclusions much more easily. In addition, it is recommended to avoid abstract and long formulations and definitions incomprehensible for students in the process of revision of the textbooks. In this regard, collaboration between authors and teachers in compilation of a substantial textbook is indispensable.

Lack of research on the topic in Kosovo, texts overloaded with theoretical information, at times difficult to comprehend and to identify facts and potential for critical thinking in existing texts, are some of the limitations of the research.

We hope that this research will encourage studies on similar topics. It is also suggested that in the future longitudinal studies are undertaken in order to explore which topics in textbooks cultivate and develop students' critical thinking skills. This kind of study would be of particular interest and would contribute to the increase of quality of textbooks and the advancement of teaching and learning in Languages and Communication field.

The textbooks that increase the level of the assessment of the content help students to develop high-level thinking skills and make them critical thinkers in new situations and challenges to be faced in the future.

\section{REFERENCES}

Agee, J. (2009). Developing qualitative research questions: A reflective process. International Journal of Qualitative Studies in Education, 22(4), 431-447. doi: 10.1080/09518390902736512 .

Bullen, M. (2007). Participation and critical thinking in online university distance education. IJEDE, 13(2), 1-32.

Creswell, J. W., \& Plano, C. (2011). Designing and conducting mixed methods research. Thousand Oaks: CA: Sage.

Creswell, J. W. (2014). Research design:Qualitative,quantitative and mixed methods approaches. SAGE Publications, Inc.

Cunningsworth, A. (1995). Choosing your coursebook. Oxford: Heinemann.

Dam, ten. G., \& Volman, M. (2004). Critical thinking as a citizenship competence:

Teaching strategies. Learning and Instruction, 14(4), 359-379. doi: 10.1016/j.learninstruc.2004.01.005. 
Errington, A., \& Bubna-Litic, D. (2015). Management by textbook: The role of textbooks in developing critical thinking. Journal of Management Education, 39(6), 774-800. https://doi.org/10.1177/1052562915594839.

Facione, P. A. (1990). Critical thinking: A statement of expert consensus for purposes of educational assessment and instruction (Delphi Report). Fullerton: The California Academic Press.

Fredriksson, \& Olsson. (2006). English textbook evaluation: An investigation into criteria for selecting English textbooks. Malmo University Electronic Publishing.

Grey, J. (2000). The ELT course book as cultural artefact: How teachers censor and adapt. ELT Jurnal, 54(3), 274-283. doi: 10.1093/elt/54.3.274.

Halpern, D. (2003). Thought and knowledge: An introduction to critical thinking. New Jersey: Lawrence Erlbaum Ass.

Harmer, J. (2007). The practice of english language teaching. Edinburgh: Pearson Education Ltd.

Harris, T., \& Rowe, A. (2006). English exploring 1. Peje: Dukagjini.

Haycroft, J. (1998). An introduction to English language teaching. London: Longman.

Hutchinson, T., \& Torres, E. (1994). The textbook as agent of change. ALT Jurnal, 48(4), 315-328.

Lipman, M. (1984). The cultivation of reasoning through philosophy. Educational Leadership, 42(1), 51-56.

Loeb, S., Dynarski, S., McFarland, D., Moris, P., Reardon, S., \& Reber, S. (2017). Descriptive analysis in education:A guide for researchers. Washington, DC: U.S. Department of Education: Institute of Education Sciences.

Lynch, B. (1996). Language program evaluation: Theory and practice. Cambridge: Cambridge University Press.

McGrath, I. (2002). Materials evaluation and design for language teaching. Edinburgh: UK: Edinburgh University Press.

MEST. (2016). Curriculum framework on pre-university education of the republic of Kosovo. Prishtina: Blendi.

Ornstein,A. C., \& Hunkins, F. P. (2003). Curriculum, base, principles and problems. Tirane: Institute of pedagogical studies.

Pinar, W. (2013). International handbook of curriculum research. New York: Routledge.

Remillard, J. (2005). Examining key concepts in research on teacher's use of mathematics curricula. Review of Educational Research 75(2), 211-246. doi: 10.3102/00346543075002211. 
Ruel, E., Wagner, W. E.,, \& Gillespie, B. J. (2016). The practice of survey research: Theory and applications. London: UK: Sage.

Sheldon, L. (1988). Evaluating ELT textbooks and materials. ELT Journal, 42(4), 237246.

Snyder, L. G., \& Snyder, M. J. (2008). Teaching critical thinking and problem solving skills. The Delta Pi Epsilon Journal 1(2), 90-99.

Steele, J., \& Meredith, K. (2002). Structures for developing critical thinking during the curriculum. Prishtina: KEC.

Syla, X. (2007). Reading 5. Prishtina: School book.

Thaci, J. (2010). The problems of textbooks shcool. Prishtina: BORN.

Valverde, G., Bianchi, L. J., Wolfe, R., Schmidt, W. H., \& Houang, R. T. (2002). Using TIMSS to investigate the translation of policy into practice through the world of textbooks. Dordrecht, Netherlands: Kluwer.

Walker, D. (2002). Fundamentals of curriculum. Passion and professionalism. New York: Routledge.

Willingham, D. T. (2008). Critical thinking, Why is it so hard to teach? Arts Education Policy Review, 109(4), 21-32.

Zohar, A. (2004). Higher order thinking in science classrooms: Students 'Learning and Teachers`Professional Development. Kluwer academic publishers.

Zylfiu, N. (2011). Didaktika. Prishtina: Printing Press 